This item was submitted to Loughborough's Research Repository by the author.

Items in Figshare are protected by copyright, with all rights reserved, unless otherwise indicated.

\title{
A computational model of the human head and neck system for the analysis of whiplash motion
}

PLEASE CITE THE PUBLISHED VERSION

http://dx.doi.org/10.1533/ijcr.2004.0302

\section{PUBLISHER}

Taylor \& Francis (@ Woodhead Publishing Ltd)

\section{VERSION}

AM (Accepted Manuscript)

\section{PUBLISHER STATEMENT}

This work is made available according to the conditions of the Creative Commons Attribution-NonCommercialNoDerivatives 4.0 International (CC BY-NC-ND 4.0) licence. Full details of this licence are available at: https://creativecommons.org/licenses/by-nc-nd/4.0/

\section{LICENCE}

CC BY-NC-ND 4.0

\section{REPOSITORY RECORD}

van Lopik, David W., and Memis Acar. 2019. "A Computational Model of the Human Head and Neck System for the Analysis of Whiplash Motion”. figshare. https://hdl.handle.net/2134/22050. 


\title{
A Computational Model of the Human Head and Neck System for the Analysis of Whiplash Motion
}

\author{
D W van Lopik* and M Acar* \\ * Mechanical and Manufacturing Engineering, Loughborough University, LE11 3TU, UK.
}

\begin{abstract}
This paper presents the development and validation of a three-dimensional multi-body model of the human head and neck for the study of whiplash motion. The model has been validated against experimental data for small and large static loading conditions. The resulting main and coupled displacements of the individual motion segments have been shown to be accurate and the moment generating capacity of the neck muscle elements realistic. The model has been used for the dynamic simulation of impacts in frontal, lateral and rear-end directions. For rear-end impacts the characteristics of 'whiplash' motion have been accurately reproduced in terms of head and vertebral kinematics The model results with active musculature suggest that, for rear-end impact, the influence of active muscle response is unable to significantly alter the head and neck kinematics of an initially unaware occupant but will affect the forces developed in the cervical soft-tissues.
\end{abstract}

\section{INTRODUCTION}

Injury to the human neck is a frequent consequence of automobile accidents and has been a significant public health problem for many years. The term 'whiplash' has been used to describe these injuries in which the sudden differential movement between the head and torso leads to abnormal motions within the neck causing damage to its soft tissue components. 'Whiplash' can occur in all vehicle impact directions as well as a result of other mishaps but is most commonly reported as a consequence of rear-end impacts. It has been estimated that $80 \%$ of personal injury claims made against British Insurers are related to Whiplash injury, costing around $£ 1$ billion annually with this figure rising yearly [1].

The mechanism of injury is not fully understood however there have been a number of different hypotheses offering explanations for the source of neck pain following 'whiplash' motion [2-8]. In a rear-end collision the head effectively remains still while the torso accelerates forwards, the lower cervical spine is forced into hyperextension and the upper into hyperflexion producing a characteristic ' $S$ ' shaped curvature of the neck. The heads inertia can lead to a situation of high shear in the top of the neck causing overstretching of the ligaments and joint capsules while non-physiological levels of extension in the lower neck can have potentially damaging effects on the anterior soft tissues. Many of the soft-tissue components of the neck have been identified as possible injury sites [9-11].

Although many different theories have been proposed no definitive answer on the cause of 'whiplash' injury has yet been established. Biomechanical research is ongoing in the field of impact analysis with many different experimental and computational methods being used to try and determine the mechanisms of injury and ultimately to improve vehicle safety. Experimental research and mathematically based computer modelling are continually used to study the behaviour of the head and neck, particularly its response to trauma during automobile impacts.

The goal of this study was to develop a three-dimensional computational model of the human head and cervical spine that could accurately predict the dynamic response of the head and neck to various automobile impact situations. This paper presents the completed model and it's application to ‘whilash' analysis.

A relatively large number of computational models of the human head and neck have been developed over the last 30 years with each generation having greater anatomical detail as modelling techniques have improved and computers have advanced. Early models were two-pivot lumped parameter models where the mechanical behaviour of the neck is represented by a single neck link with neck-torso and neck-head pivots. These simple two-pivot models have been used for analysis of head-neck global kinematics in volunteer and cadaver experiments [12-14]. Multibody models are an extension of these simple lumped parameter models with a greater amount of detail. Rigid bodies are used to represent the head and cervical vertebrae interconnected with massless spring and damper elements to represent the disc, ligaments and muscles. Finally finite-element modelling allows the complete reconstruction 
of the bones, joints, ligaments, discs and muscles of the cervical spine in terms of one-, two- or threedimensional geometric elements. Each element is then given its respective material properties so the internal stresses and strains can be calculated and the response of the various structures and tissues can be studied when subjected to external loads.

Although in theory finite element models are able to represent the cervical spine and its soft tissues in their entirety and the development of this type of model has dominated in the last 10 years, the level of detail actually included is not significantly greater than that seen in the multibody model of De Jager [15]. The geometry of the models are mostly based on different data, obtained from a specific subject then scaled to represent a $50^{\text {th }}$ percentile male while the mechanical characteristics and validation of both finite element and multibody models are mostly based on the same experimental data. For most models large simplifications and assumptions have been made to allow for more efficient simulations or to fill in missing material properties. The soft tissue properties have been lumped into single intervertebral joints $[16,17]$, the representation of the upper cervical joints have been by simple pin joints $[18,19]$ and very few models have included muscle properties and studied the effects of muscle activation. Another major disadvantage of detailed finite-element models is the exceptionally large run times they require, for example the head-neck model of Halidin et al. [20] took around 45hrs for a $25 \mathrm{~ms}$ simulation, compared against de Jagers model that could run a $200 \mathrm{~ms}$ simulation in just under 20 minutes. For evaluation of new safety systems, where small improvements and modifications are to be made based on simulation results, short, reliable run times are advantageous if not essential.

All models are limited by the available material properties and as more experiments are completed on the response of the soft tissues of the cervical spine they are readily used to define more detail in headneck models and to validate their response. One area where material properties are lacking is the intervertebral discs, dynamic response of which are still largely uncharacterised, with most modellers choosing linear properties based on quasi-static experimental data. Although complex finite-element representations of the intervertebral discs have been included in some head-neck models it is believed, due to the lacking material properties, that they offer no greater accuracy then the simple six-degree of freedom spring damper arrangement used by de Jager.

\section{METHODS}

\section{Model Development}

The computational model developed reproduces the head and neck of an adult in an upright sitting position. The arrangement of the head and cervical vertebrae represents the natural lordosis of the neck with mid-sagittal symmetry assumed. A simpler version of the model was first presented in a preliminary paper by van Lopik and Acar [21]. The latest model incorporates greater geometric complexity along with a more accurate representation of the cervical muscles.

Implemented in visualNastran 4D, a dynamic simulation and analysis software package, the model comprises nine rigid bodies with detailed geometry representing the head, seven cervical vertebrae, and the first thoracic vertebrae. The rigid bodies are interconnected by spring and damper constraints representing the soft-tissues of the neck. (Non)-linear viscoelastic 'bushing' constraints connect adjacent vertebrae representing the cervical intervertebral discs, non-linear viscoelastic spring-damper elements are used to describe the cervical ligaments and frictionless rigid-body contact idealizes facet joint behaviour. The depiction of the upper cervical vertebrae ( $\mathrm{C} 1$ and $\mathrm{C} 2$ ) differs from the middle and lower bodies. The dens process of the axis is modeled as well as the concave-convex interaction of the atlanto-odontoid and atlanto-occipital articular joints. 19 muscle groups of the head and neck are included in the model represented by connections of linear actuators allowing the muscles to curve around the vertebrae during neck bending. Muscle mechanics are handled by an external application that runs within Matlab and Simulink providing both passive and active muscle behaviour. Figure 1 shows the final neck model from occiput to T1 with all the soft tissue elements and musculature attached. 

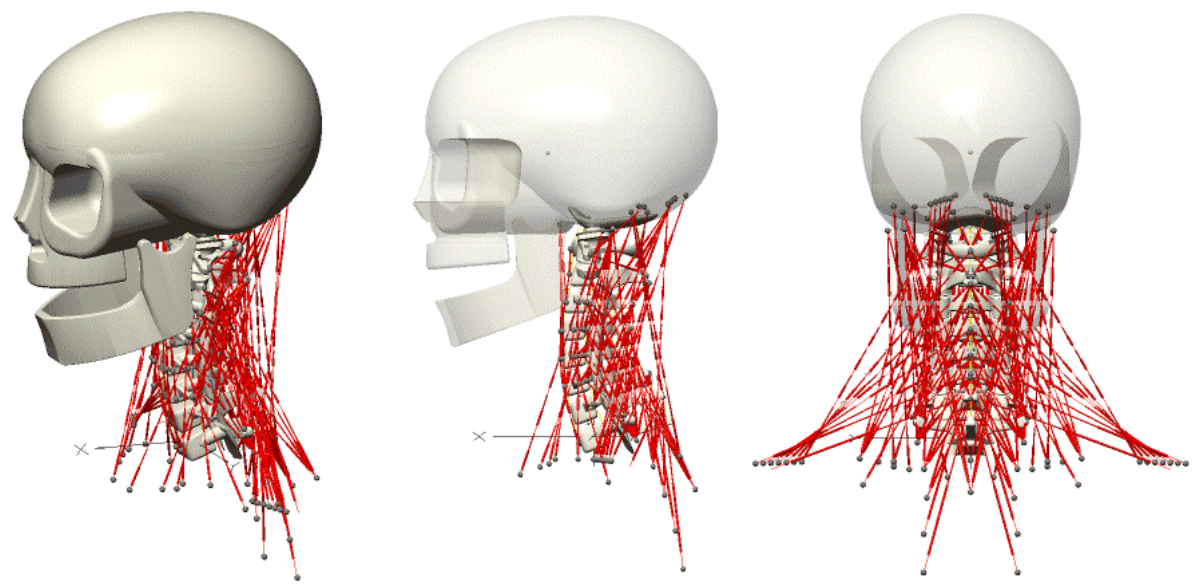

Figure 1. Isometric, lateral and rear view of the final head/neck model with all muscle elements in place. The skull shown transparent in lateral and rear view to show attachments points of muscle elements.

\section{Model Validation}

The completed model has been rigorously validated against experimental results, ranging from the individual motion segment response to the dynamic response of the whole head neck model to frontal and lateral impacts. The response of the motions segments to small and large static loading was found to be in good agreement with experimental results in all directions of loading. The coupling characteristics of the cervical spine were shown to be accurately reproduced and the moment generating capacity of the muscles elements was found to be realistic. The complete head-neck model has been used to simulate $15 \mathrm{~g}$ frontal and $7 \mathrm{~g}$ lateral impacts with the resulting motion compared against response corridors derived from sled acceleration tests using human volunteers. The effect of passive and fully active muscle behaviour was investigated and was shown that for both impact directions the inclusion of active muscle tensioning results in closest agreement with the experimental data. Good agreement was seen for both impact directions. For more information regarding the model development and validation the reader is referred to [22].

\section{SIMULATION OF WHIPLASH}

In an effort to validate the model for rear-end impacts the model has been used to simulate the benchtop trauma sled experiments conducted by Panjabi and co-workers [11, 23-25] performed using isolated cervical spine specimens. These studies used cadaveric cervical spine specimens stripped of all non-ligamentous soft tissues mounted to a bench top sled device where an acceleration pulse is applied to the base of the specimen to reproduce whiplash trauma. The acceleration input was a triangular pulse with duration of $105 \mathrm{~ms}$. Peak accelerations of $2.5 \mathrm{~g}, 4.5 \mathrm{~g}$. $6.5 \mathrm{~g}$ and $8.5 \mathrm{~g}\left(1 \mathrm{~g}=9.8 \mathrm{~m} / \mathrm{s}^{2}\right)$ were studied [11]. The resulting rotation, vertical and horizontal translation of the head with time for the $8.5 \mathrm{~g}$ trauma were presented along with the maximum vertebral rotations reached at each level of the cervical spine for each trauma class. A detailed description of the resulting head and neck motion was also presented. These tests are an alternative to experiments using volunteers, whole body cadavers or anthropometrical crash dummies and have been shown to effectively simulate whiplash trauma.

\section{Simulation without muscles}

To simulate the bench-top sled tests all muscles were removed from the head-neck model. The motion of T1 was constrained so only translation along the $\mathrm{x}$-axis was possible. The skull model was used as this was based on a $50^{\text {th }}$ percentile human head and so is comparable to the surrogate head used in the experiments. No gravitational effects are simulated at this stage. Unfortunately the actual acceleration profiles used in the experiments are not presented so idealized acceleration profiles are used as input to the model as described by Raynak and Ching [26]. The profiles are triangular with the same 105ms duration and corresponding peak accelerations (Figure 2). The resulting head rotations and translations 
are compared against the results for the $8.5 \mathrm{~g}$ trauma class and the maximum vertebral rotations are compared at all levels.

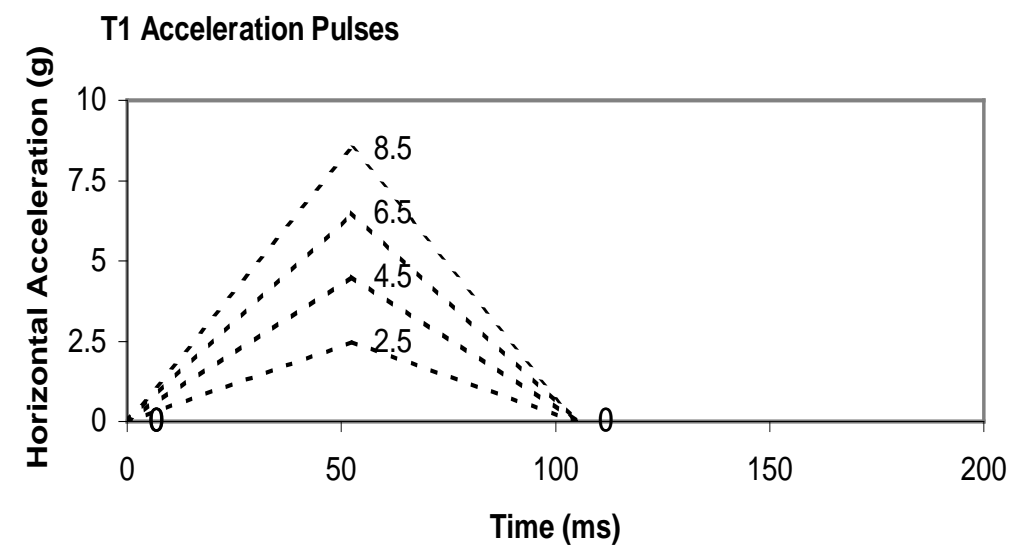

Figure 2: Horizontal T1 acceleration profiles used as input to the head-neck model for the four classes of impact trauma, 2.5-8.5g.

\section{Results}

The overall response of the ligamentous spine model to the $8.5 \mathrm{~g}$ trauma class is shown schematically in Figure 3. Figure 4 shows the head rotation and head vertical and horizontal translation for the $8.5 \mathrm{~g}$ trauma class compared to the experimental results of Grauer et al. [11]. The model shows a similar response to the cadaveric spine specimen however the maximum rotation of the head is around $10^{\circ}$ greater in the model. Following the maximum rotation and maximum posterior translation of the head the model rebounds slightly slower than is seen with the spine specimen. The vertical displacement of the head with respect to the torso is in good agreement with the experimental results reaching a peak of around $5 \mathrm{~cm}$ below the initial height.

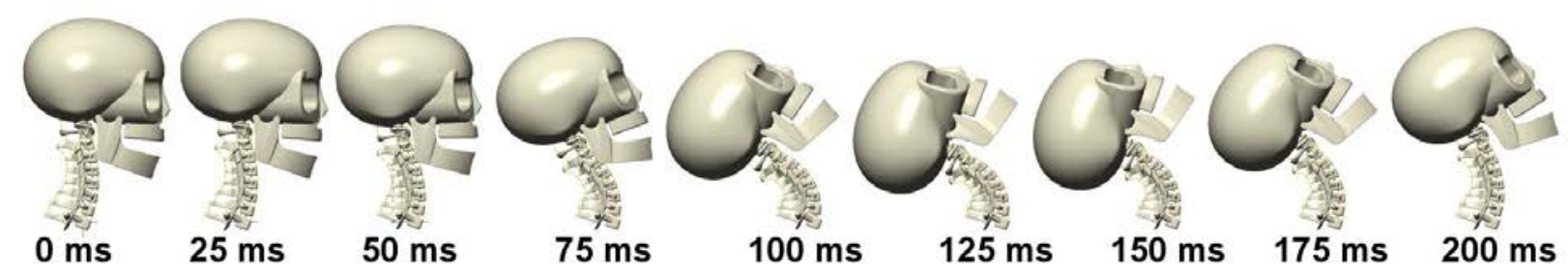

Figure 3. Kinematics of ligamentous head-neck model for $8.5 \mathrm{~g}$ rear-end impact trauma at $25 \mathrm{~ms}$ time intervals.

During the acceleration portion of the whiplash the head translates posteriorly and inferiorly with respect to T1 and the spine extends. Over the 50-75ms time period the development of the characteristic S-shaped curvature of the cervical spine is observed. It can be seen from the vertebral rotation graphs shown in Figure 5 that during this time period the upper levels of the spine (C0-C3) are flexed while the lower levels (C5-T1) are extended as was seen in the experimental results. The 75$100 \mathrm{~ms}$ time period sees the upper vertebrae of the model change from flexion to extension as the whole model becomes more and more extended into a C-shaped curvature as also observed in the isolated spine experiments. Maximum extension of the head and neck is reached at approximately $125 \mathrm{~ms}$, slightly later than the experimental results. In the later stages of trauma the head returns towards its initial starting configuration. 
Figures 6 and 7 compare the maximum intervertebral rotations of the model for the four trauma classes simulated with those reported for the spine specimens. Figure 6 shows the maximum flexion and extension of the upper three levels of the cervical spine. The graphs show that although the upper levels are initially forced into flexion in the model, the levels of flexion experienced are noticeably smaller than the isolated spine specimens indicating that perhaps the model is too stiff in flexion in these areas. The levels of extension experienced in the later stages of impact agree more favourably with the experimental data. Figure 7 shows the maximum intervertebral extension rotations experienced by the lower five levels of the spine model. Although small levels of flexion were experienced (less than $0.3^{\circ}$ at all levels) for some of the lower segments in the early stages of impact they are not presented here as they are thought small enough to be insignificant to the overall response. Comparable levels of extension are seen at each level for each trauma class; noticeable differences can be seen at C3-C4 for 6.5g and at C6-C7 for both 4.5g and 8.5g impacts (no data was reported for C7$\mathrm{T} 1$ at 4.5g). Generally level C6-C7 appears to be too stiff when compared to the experimental results. As would be expected the response of the model shows increasing levels of maximum flexion and extension for the increasing severity of impact, this pattern however is not clear in the experimental results of the cadaveric ligamentous spine specimens.

\section{$8.5 \mathrm{~g}$ Trauma}

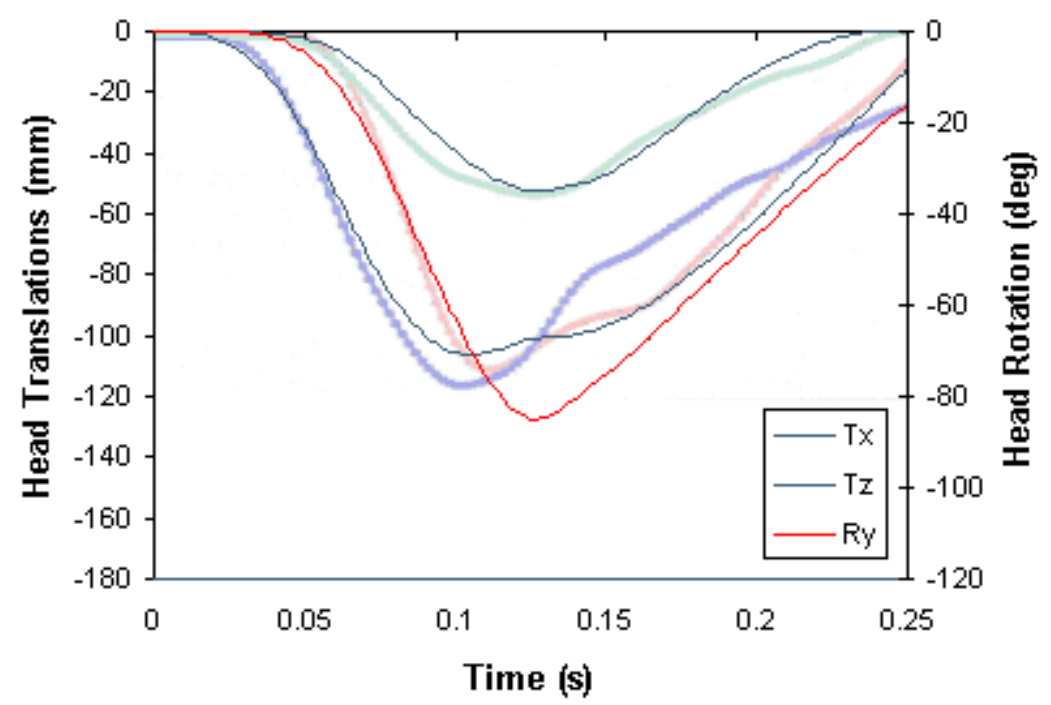

Figure 4. Head rotation, and translations with respect to T1 versus time. Simulation of 8.5g bench-top trauma test using the ligamentous head-neck model compared with experimental results (shown in respective faded colours). Negative values indicate posterior (-x) and inferior (-z) translations and extension (-y) rotations. 


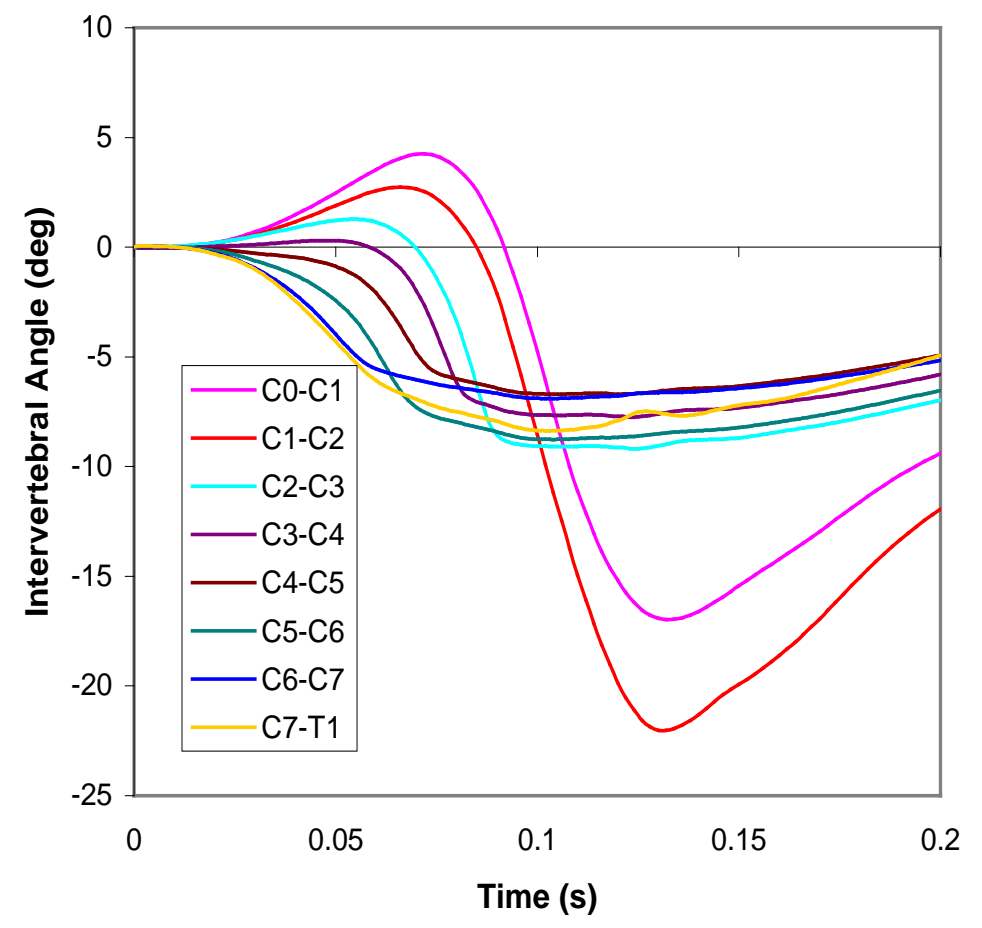

Figure 5. Intervertebral rotations at each level of the head-neck model in response to the applied 8.5g acceleration pulse at T1. Positive rotations indicate flexion response while negative values indicate extension.
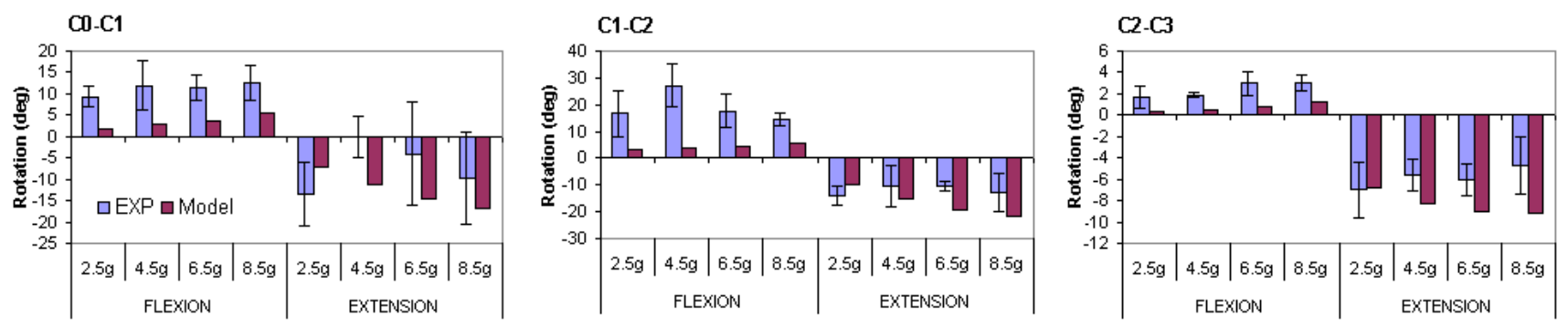

Figure 6. Maximum intervertebral angles achieved during the four whiplash trauma classes for the upper three motion segments of the ligamentous cervical spine model, shown against the average \pm SD of the experimental data. 

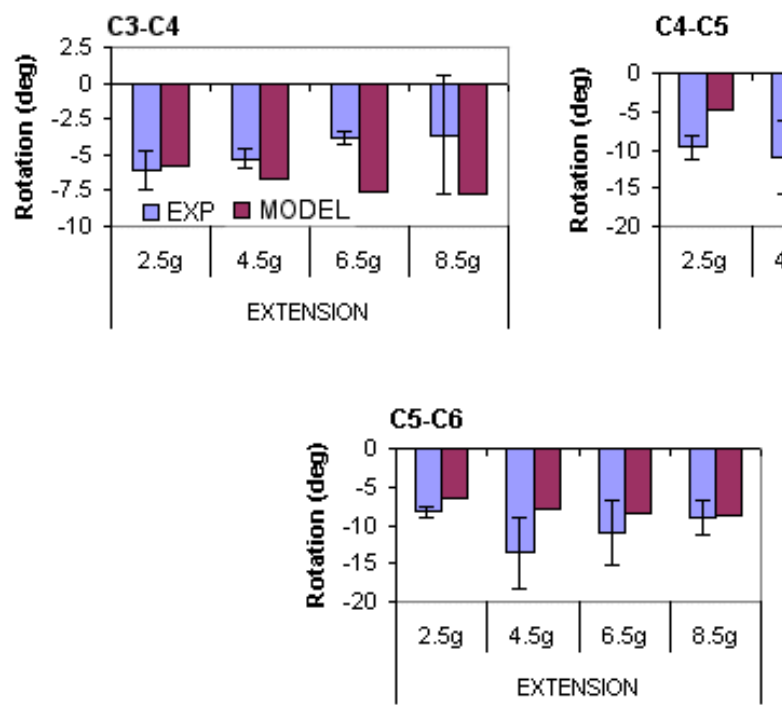

C6-C7

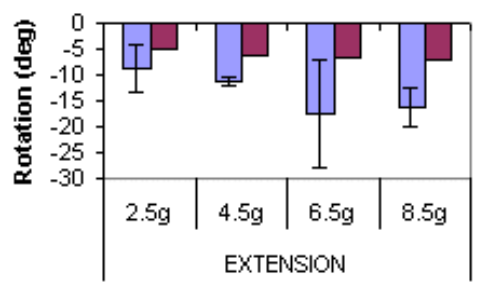

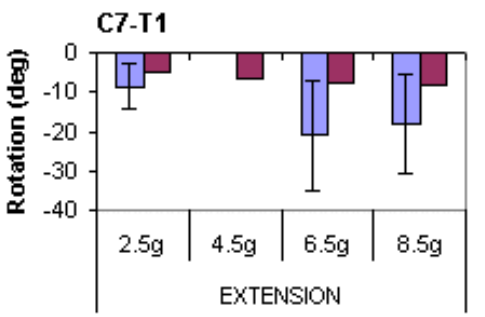

Figure 7. Maximum intervertebral angles achieved during the four whiplash trauma classes for the lower five motion segments of the ligamentous cervical spine model, shown against the average $\pm \mathrm{SD}$ of the experimental data. The lower segments of the model did not experience significant levels of flexion during any of the trauma classes so only maximum extension is shown.

\section{Effect of Musculature on Head-Neck Motion}

Following the validation of the ligamentous model against the bench-top trauma sled experimental results the effects of musculature on the head and neck response was investigated. All the neck muscles were added back to the model to study the effects of active and passive muscle behaviour on the head-neck motion for the same $8.5 \mathrm{~g}$ impact as described previously.

\section{Simulation Set-up}

The model with all muscles in place was set-up in the same manner as described for the model without muscles. The same acceleration pulse was used as input to T1 to simulate the $8.5 \mathrm{~g}$ sled test with the onset of the acceleration delayed by $50 \mathrm{~ms}$. For active muscle response the onset time of muscle activation was set at $75 \mathrm{~ms}$ after the start of the simulation, $25 \mathrm{~ms}$ after the onset of $\mathrm{T} 1$ acceleration, at which point all muscles were given $100 \%$ activation. For the passive response, the activation level of all muscles was left at 0 for the duration of the simulation. The response of the active and passive model can be assumed to represent an initially relaxed occupant with and without muscle response.

\section{Simulation Results}

Figure 8 depicts the head-neck response with active musculature over the 250ms $8.5 \mathrm{~g}$ rear-end impact simulation. A similar overall response is obtained as was seen for the ligamentous cervical spine model. It can be seen from the blue force vectors how muscle force is developed in the anterior muscle groups of the neck in response to the initial retraction motion of the head with respect to T1 and continues to increase as the head and neck extend. Forces are developed in the posterior muscle groups following the rebound of the head. Figure 9 compares the head and neck rotation of the passive and active spine model. Very little difference is seen between the two responses, both reaching the same level of head extension at the same time. Peak neck rotation is reduced slightly with quicker rebound of the neck observed with muscle tensioning. 


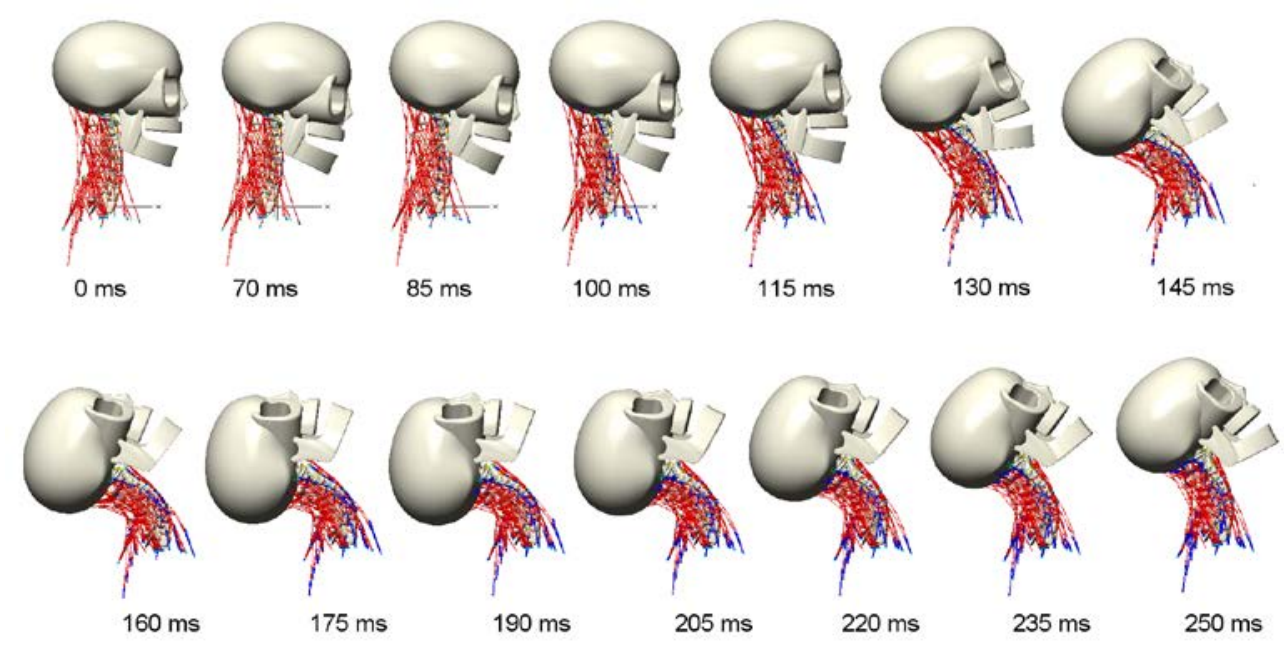

Figure 8 . Time history of the head and neck response to $8.5 \mathrm{~g}$ rear-end impact with $100 \%$ active musculature.
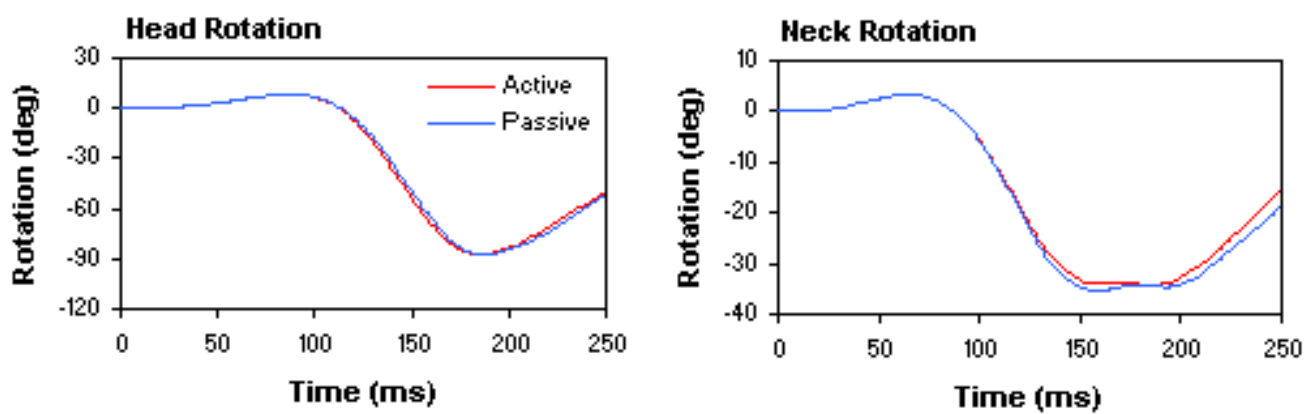

Figure 9. Head and neck rotation in response to the $8.5 \mathrm{~g}$ rear-end impact simulation with active and passive muscle behaviour.

Figure 10 compares the peak forces and moments developed in the intervertebral discs for the passive, active and ligamentous cervical spine model. With active musculature the level of compression in the discs is significantly increased at all levels except for C7-T1. For the upper four intervertebral discs the peak compressive force is over double that seen for the ligamentous model. The peak tensile forces in the lower cervical spine are increased with passive muscle properties, with active musculature only the C2-C3 disc experiences any level of tension with a peak value similar to the ligamentous spine model. Shear forces in the disc are generally decreased with active muscles while the passive model shows increases in peak posterior shear at all levels. The peak extension moment on the discs is fairly similar for the upper four levels for the active and passive model, both being around $30 \%$ higher than with the ligamentous model. For the lower two levels, C6-T1, the maximum torque on the discs with active musculature is about the same as experienced by the ligamentous model while the passive model remains around $15 \%$ higher. 

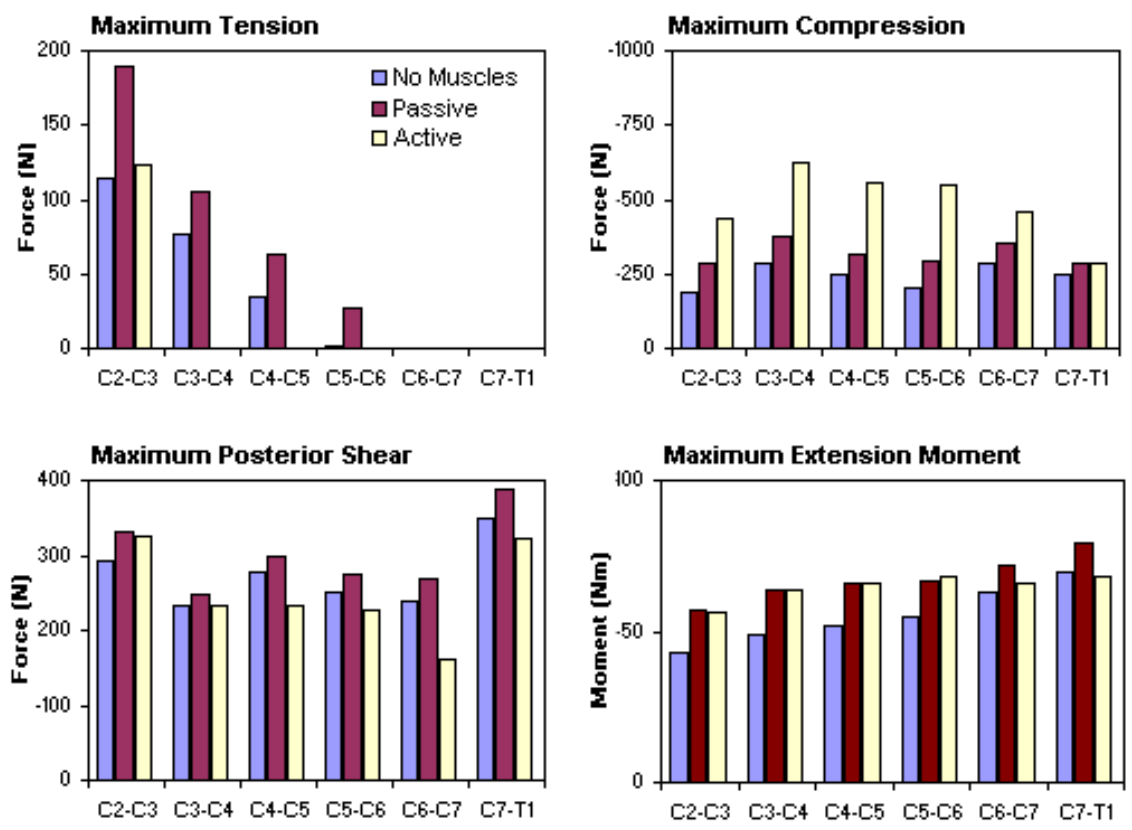

Figure 10. Comparison of maximum disc forces and moments for the head-neck model in response to $8.5 \mathrm{~g}$ acceleration impact with and without the influence of active and passive musculature.

Due to the increased compressive forces in the neck generated by the active muscle response the peak forces experienced by the facet joints are significantly increased. Figure 11 shows the maximum facet force on the left articular facets and also the peak force on the dens facet. The passive response of muscles has little affect on the peak loads of the lower cervical spine facets showing similar values to those seen with the ligamentous model. The upper cervical spine facets have greatly increased maximum load with the inclusion of muscles to the model both with active and passive response.

Small variations were seen in peak ligament forces with the inclusion of active and passive musculature. Table 1 presents the maximum ligament forces for the active muscle simulation as percentages of dynamic failure load. It can be seen that the Alar ligaments reach $100 \%$ of their predicted dynamic failure load indicating their vulnerability in rear-end impact. The anterior longitudinal ligaments also reach relatively high loads with the ALL of C2-C3 being over $50 \%$ the dynamic failure force.

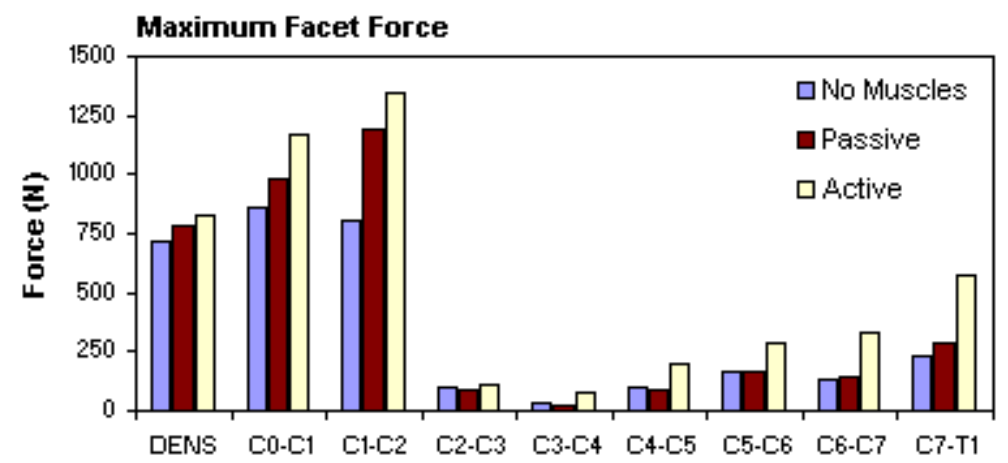

Figure 11. Comparison of maximum facet forces for the head-neck model in response to

8.5g acceleration impact with and without the influence of active and passive musculature. 
Table 1: Peak ligament forces as percentage of dynamic failure force for $8.5 \mathrm{~g}$ rear-end impact simulation with active musculature.

$\mathrm{C} 0-\mathrm{C} 2 \quad \mathrm{C0}-\mathrm{C} 1 \quad \mathrm{C} 1-\mathrm{C} 2 \quad \mathrm{C} 2-\mathrm{C} 3 \quad \mathrm{C} 3-\mathrm{C} 4 \quad \mathrm{C} 4-\mathrm{C} 5 \quad \mathrm{C} 5-\mathrm{C} 6 \quad \mathrm{C} 6-\mathrm{C} 7 \quad \mathrm{C} 7-\mathrm{T} 1$

\begin{tabular}{|c|c|c|c|c|c|c|c|c|c|}
\hline Ligament & & & & & & & & & \\
\hline ALL & & & & 56 & 30 & 23 & 14 & 10 & 15 \\
\hline PLL & & & & 6 & 3 & 1 & 1 & 1 & 1 \\
\hline $\mathrm{FL}$ & & & & 15 & 7 & 4 & 3 & 3 & 3 \\
\hline ISL & & & & 25 & 16 & 8 & 11 & 15 & 16 \\
\hline$C L$ & & 21 & 28 & 6 & 7 & 5 & 7 & 4 & 1 \\
\hline ALAR & 100 & & & & & & & & \\
\hline APICAL & 43 & & & & & & & & \\
\hline AM & & 10 & 42 & & & & & & \\
\hline PM & & 16 & 21 & & & & & & \\
\hline TL & & & 6 & & & & & & \\
\hline TM & 20 & & & & & & & & \\
\hline
\end{tabular}

Note: Dynamic failure force calculated as 2.7 times static failure force of each ligament as reported in [27-29].

\section{DISCUSSION}

The paper has presented the development and validation of a computational model of the human head and neck model complex. The model has been used to simulate rear-end impacts and to investigate the role of the cervical muscles on the response of the head and neck to 'whiplash' motion. The model has first been implemented without musculature to simulate bench-top trauma experiments using isolated ligamentous cervical spine specimens. Uniform T1 acceleration pulses of increasing severity have been used to recreate 'whiplash' motion and the resulting head and vertebral rotations compared to the experimental findings.

Qualitatively the model successfully reproduces the characteristic motion of the head and neck when subjected to rear-end impact. From the onset of T1 acceleration shear forces are built up in the discs due to the forward movement of T1 relative to the head. The shear forces are transferred from the lowest level upward through the soft-tissue components of the neck model, creating an extension moment between the lower vertebrae. The differential movement between the head and $\mathrm{T} 1$ causes initial flexion in the upper joints as the head translates backward, without rotation, relative to T1. The formation of this ' $S$ ' shaped curvature of the neck with flexion of the upper and extension of the lower joints is typical of 'whiplash' motion and is a phenomenon that does not occur under normal physiological movements of the head. Following the development of the ' $\mathrm{S}$ ' curve, the neck then goes into extension at all levels as the head rotates rearward to a point of maximum extension before rebounding towards its initial position.

For the most severe impact simulated the resulting head rotation and displacement agrees reasonably well with the experimental results however the maximum extension of the head is greater than seen with the spine specimens. The maximum intervertebral rotations are shown to increase with increasing impact severity and agree reasonably well with reported values.

Following the validation of the ligamentous spine model the cervical musculature was added back to the model to study the effects of active and passive muscle response on the head-neck motion, and internal loads when subjected to the most severe 'whiplash' acceleration. Little difference was observed between the active and passive response in terms of head and neck rotation however muscle tensioning significantly altered the internal loads in the soft-tissue components for the activation scenario simulated. It would appear that although the anterior muscle groups of the neck (flexors) are 
able to generate significant force in reaction to the retraction phase of the head relative to the torso their attachments to the head and neck and subsequent lines of action make them not well suited to resisting this translatory motion, instead generating increasing levels of compression in the neck. Peak disc compression forces and peak facet forces are dramatically increased with the inclusion of muscle tensioning while the levels of posterior shear in the discs are reduced.

Only one activation state has been simulated which represents an initially unaware occupant with a muscle reflex delay of $75 \mathrm{~ms}$ after which all cervical muscles become maximally activated. Further simulations exploring different levels of activation, reflex delay and co-contraction schemes need to be investigated to properly determine the possible influence of active musculature. Also the affect of pretensed muscles should be studied.

Analysis of peak ligament forces shows the Alar ligaments to be at risk of injury in the $8.5 \mathrm{~g}$ rear-end impact however this peak in force occurs in conjunction with maximum extension of the head and so would most likely be prevented by the use of a head restraint as would the peak forces for the majority of the upper cervical spine ligaments. In the lower cervical spine the anterior longitudinal ligaments reach a peak in force prior to the development of maximum head and neck extension due to the local extension of the lower vertebrae in the formation of the ' $S$ ' shaped curvature of the neck. The inclusion of a head restraint to the model simulation would identify if these ligament forces can be prevented and would help determine the required positioning of a head restraint to best prevent excessive loads develop in the soft-tissue components.

In conclusion the ligamentous spine model has been validated with reasonable success against experimental results using human cervical spine specimens for simulated rear-end impact. The characteristics of 'whiplash' motion have been accurately reproduced in terms of head and vertebral kinematics. The soft-tissue loads have been investigated and the effects of gravity studied. Finally all the muscle elements were added back to the model to study the effects of active and passive muscle behaviour. The model results with active musculature suggest that the influence of active muscle response is unable to significantly alter the head and neck kinematics of an initially unaware occupant but will affect the forces developed in the cervical soft-tissues.

\section{ACKNOWLEDGMENTS}

The financial support of the EPSRC is gratefully acknowledged.

\section{REFERENCES}

1 Thatcham, 'Whiplash Research'. THATCHAM.ORG, the motor insurance repair research centre, 2001. http://www.thatcham.org/

2 I Macnab, ‘Acceleration injuries of the cervical spine’, Journal of Bone and Joint Surgery, 1964, 46.

3 L Penning. 'Acceleration injury of the cervical spine by hypertranslation of the head. Part 1: Effect of normal translation of the head on cervical spine motion: a radiologic study’, European Spine Journal, 1992, 1, 7-12.

4 L Penning, 'Acceleration injury of the cervical spine by hypertranslation of the head. Part 2: Effect of normal translation of the head on cervical spine motion: discussion of literature data’, European Spine Journal, 1992, 1, 13-19.

5 B Aldman, 'An analytical approach to the impact biomechanics of head and neck injury', In Proceedings $30^{\text {th }}$ Annual AAAM Conference, 1986, 439-454.

6 M Y Svensson, B Aldman, H A Hansson, P Lovsund, T Seeman, A Suneson, and T Ortengren, 'Pressure effects in the spinal canal during whiplash motion - a possible cause of injury to the cervical spinal ganglia', In International IRCOBI Conference on the Biomechanics of Impacts, 1983, 189-200.

7 K Ono, K Kaneoka, A Wittek, J Kajzer, 'Cervical injury mechanism based on the analysis of human cervical vertebral motion and head-neck-torso kinematics during low speed rear impacts', In Proceedings of the $41^{\text {st }}$ Stapp Car Crash Conference, 339-356. Society of Automotive Engineers, 1997, SAE Paper No. 973340. 
8 N Yoganandan, F A Pintar, and M Klienberger, ‘Cervical spine vertebral and facet joint kinematics under whiplash’, Journal of Biomechanical Engineering, 1998, 120: 305-307.

9 K Kaneoka, K Ono, S Inami, and K Hayashi, ‘ Motion analysis of cervical vertebrae during whiplash loading’, Spine, 1999, 24(8): 763-770.

10 B A Winkelstein, R W Nightingale, W J Richardson, and B S Myers, ' The cervical facet capsule and its role in whiplash injury’, Spine, 2000, 23(10): 1238-1246.

11 J N Grauer, M M Panjabi, J Cholewicki, K Nibu, and J Dvorak, 'Whiplash produces an S-shaped curvature of the neck with hyperextension at lower levels’, Spine, 1997, 22(21): 2489-2494.

12 J Wisman, E Van Oorshot, and H J Woltring, ‘Omni-directional human head-neck response’, 30 ${ }^{\text {th }}$ Stapp Car Crash Proceedings, pages 313-331. Society of Automotive Engineers. 1986, SAE Paper No. 861893.

13 J Wisman, M Philippens, E Van Oorshot, D Kallieris, and R Mattern, 'Comparison of human volunteer and cadaver headneck response in frontal flexion', $31^{\text {th }}$ Stapp Car Crash Proceedings, pages 1-11. Society of Automotive Engineers, 1987, SAE Paper No. 872194.

14 J Thunnissen, J Wismans, C L Ewing, and D J Thomas, 'Human volunteer head-neck response in frontal flexion: A new Analysis', In Proceedings of the $39^{\text {th }}$ STAPP Car Crash Confernece, pages 439-460. Society of Automotive Engineers, 1995, SAE Paper No. 952721.

15 M J K De Jager, 'Mathematical head-neck models for acceleration impacts’, PhD Thesis, Technical University of Eindhoven, 1996.

16 D L Camacho, R W Nightingale, J J Robinette, S K Vanguri, D J Coates, and B S Myers, 'Experimental Flexibility Measurements for the Development of a Computational Head-Neck Model Validated for Near-Vertex Head Impact', In Proceedings of the $41^{\text {st }}$ Stapp Car Crash Conference, pages 473-486. Society of Automotive Engineers, 1997, SAE Paper No. 973345.

17 C A Van Ee, R W Nightingale, D L Camacho, V C Chancey, K E Knaub, E A Sun, and B S Myers, ‘ Tensile Properties of the Human Muscular and Ligamentous Cervical Spine’, In proceedings of $44^{\text {th }}$ Stapp Car Crash Conference, 2000, pages 85102. Society of Automotive Engineers.

18 M Kleinberger, 'Application of finite element techniques to the study of cervical spine mechanics', In Proceedings of the $37^{\text {th }}$ Stapp Car Crash Conference, San Antonio, TX; 261-272, 1993.

19 F Dauvilliers, F Bendjellal, M Weiss, F Lavaste, and C Tarriere, 'Development of a finite element model of the neck', In Proceedings of the $38^{\text {th }}$ Stapp Car Crash Conference, pages 77-91. Society of Automotive Engineers, 1994, SAE Paper No. 942210 .

20 P H Halidin, K Brolin, S Kleiven, H Von Hoist, L Jakobsson, and C Palmertz, 'Investigation of conditions that affect neck compression-flexion injuries using numerical techniques’, Stapp Car Crash Journal, 2000, 44, 127-138.

21 D W van Lopik and M Acar , 'The development of a multibody head-neck system for impact dynamics using VsualNstran 4D', ESDA $6^{\text {th }}$ Biennial Conference on Engineering Systems Design and Analysis, Istanbul, Turkey, 2001.

22 D W van Lopik, 'A computational model of the human head and cervical spine for dynamic impact simulation', PhD thesis, Loughborough University, UK, 2004.

23 M M Panjabi, J Cholewicki, K Nibu, L B Babt, and J Dvorak, 'Simulation of whiplash trauma using whole cervical spine specimens', Spine, 1998, 23(1): 17-24.

24 M M Panjabi, J Cholewicki, K Nibu, J Grauer, L B Babt, and J Dvorak, 'Mechanism of whiplash injury’, Clinical Biomechanics, 1998, 13: 239-249.

25 M M Panjabi, A M Pearson, S Ito, P C Ivancic, and J-L Wang, 'Cervical spine curvature during simulated whiplash', Clinical Biomechanics, 2004, 19, 1-9.

26 G C Raynak, and R P Ching, 'Dynamic sled tuning for benchtop whiplash simulation', In N. Yoganandan and F.A. Pintar, editors, Frontiers in Whiplash Trauma, Clinical and Biomechanical, pages 186-197. IOS Press, Amsterdam, 2000, ISSN 0929-6743.

27 J B Myklebust, F A Pintar, N Yoganandan, J F Cusick, D Maiman, T J Myers, and A Sances, 'Tensile strength of spinal ligaments', Spine, 1988, 13(5):526-531. 
28 N Yoganandan, S Kumaresan, and F A Pintar, F.A. 'Geometric and mechanical properties of human cervical spine ligaments’, Journal of Biomechanical Engineering, 2000, 122:623-629.

29 N Yoganandan, F A Pintar, J Butler, J Reinartz, A Sances, and S J Larson, 'Dynamic response of human cervical spine ligaments', Spine, 1989, 14(10):1102-1109. 